\title{
PRODUTIVIDADE DE CULTIVARES DE FEIJÃO DO GRUPO CARIOCA NO SUL DO ESPÍRITO SANTO
}

\author{
Leonardo José Frinhani Nóia da Rocha1 \\ Rogério de Souza Nóia Júnior ${ }^{2}$ \\ Leandro Pin Dalvi ${ }^{3}$
}

\begin{abstract}
Resumo: O cultivo do feijoeiro-comum (Phaseolus vulgaris L.) possui grande importância no cenário brasileiro, não somente no plano econômico, mas também como fator de segurança alimentar, representando um dos pilares da dieta do povo brasileiro. No estado do Espírito Santo os agricultores familiares vêm enfrentando muitos obstáculos para produzir feijão, destacando-se: a utilização de cultivares desatualizadas, sementes de baixa qualidade e dificuldade de acesso a informações técnicas. O objetivo deste projeto foi avaliar cultivares de feijão do grupo carioca visando identificar as mais aptas ao cultivo no Sul do estado. Foram utilizadas 6 cultivares, sendo 5 recém-lançadas e uma tradicional. O delineamento foi $D B C$, com 4 repetições. A variável massa de 100 grãos foi a que proporcionou maior diferenciação entre as cultivares, sendo a cultivar Carioca comum a que apresentou menor massa, e BRS Ametista a maior. Apenas as cultivares Carioca comum, BRS Notável e BRS Pontal se enquadraram na classe preferível de consumo, sendo mais indicadas para plantios que visam à comercialização. A produtividade não se diferenciou significativamente entre as cultivares avaliadas, porém, ambas ficaram acima da média de produtividade do estado.
\end{abstract}

Palavras-chave: Phaseolus vulgaris L.; Competição; Interação genótipo x ambiente.

\footnotetext{
${ }_{1}$ Agrônomo/Universidade Federal do Espírito Santo, Brasil. E-mail: leofrinhanirocha@gmail.com.

2 Agrônomo/Universidade Federal do Espírito Santo, Brasil. E-mail: rogeriosouzanoia@gmail.com.

3 Professor/Universidade Federal do Espírito Santo, Brasil. E-mail: leandropin@yahoo.com.br.
} 